\title{
Diretrizes estratégicas para a implantação da Gestão do Conhecimento Organizacional
}

\author{
Edson Pinheiro de Lima, Dr. Eng. \\ Programa de Pós-Graduação em Engenharia de Produção e Sistemas - PPGEPS \\ Pontifícia Universidade Católica do Paraná - PUCPR \\ Sérgio Eduardo Gouvêa da Costa, Dr. Eng. \\ Programa de Pós-Graduação em Engenharia de Produção e Sistemas - PPGEPS \\ Pontifícia Universidade Católica do Paraná - PUCPR
}

Heitor José Pereira, Dr. Adm.

Programa de Pós-Graduação em Administração - PPAD

Pontifícia Universidade Católica do Paraná - PUCPR

Alex Antonio Ferraresi, MSc. Adm.

Pontifícia Universidade Católica do Paraná - PUCPR

Marco Antonio Busetti de Paula, Dr. Eng.

Programa de Pós-Graduação em Engenharia de Produção e Sistemas - PPGEPS

Pontifícia Universidade Católica do Paraná - PUCPR

\begin{abstract}
As organizações têm desenvolvido novas abordagens para gerir o conhecimento organizacional, sendo este tratado como um recurso estratégico. As funções organizacionais devem desenvolver processos organizacionais e de gestão para mobilizar o conhecimento organizacional, na contínua busca pela realização da estratégia de negócios. Este trabalho desenvolve um framework teórico-conceitual para orientar o processo de implantação da Gestão do Conhecimento em uma empresa do setor de energia. Tem como fundamentos: o alinhamento estratégico da função Gestão do Conhecimento, a consideração dos processos e práticas existentes na empresa para a Gestão do Conhecimento, o tratamento sistêmico da implantação da Gestão do Conhecimento, conciliando as abordagens comportamentais e as baseadas nas tecnologias de informação e comunicação, o desenvolvimento de um processo participativo e estruturado para a geração de um conjunto de premissas e diretrizes orientativas. A grande contribuição deste artigo é a construção de uma racionalidade, tanto estrutural como processual, para a geração de um conjunto de diretrizes estratégicas para a implantação da Gestão do Conhecimento em uma organização. Através de exemplos, são ilustrados o conteúdo, a estrutura e a dinâmica associados a um conjunto de premissas e de diretrizes estratégicas para a implantação da Gestão do Conhecimento em uma dada organização.
\end{abstract}

Palavras-chave: diretrizes estratégicas; gestão do conhecimento; gestão estratégica do conhecimento.

Organizations have been developing new approaches to the organizational knowledge management, and this knowledge has been considered as a strategic resource. The organizational functions should develop organizational and management processes for the organizational knowledge deployment, looking for the business strategy accomplishment. This paper develops a conceptual-theoretical framework to guide the knowledge management implementation in an enterprise from the energy industry area. It has as fundamentals: the knowledge management function strategic alignment; the existing enterprise knowledge processes and practices acknowledgement; the utilization of a systemic approach for the knowledge management implementation that conciliates the behavioral and the technological approaches; the development of a structured and participative approach to the premises and guidelines formulation. The main contribution of this paper is both a structural and a process rationality construction, to the strategic guidelines conception for the organization knowledge management process implementation. Some examples are used to illustrate the contents, structure and dynamics of a set of premises and strategic guidelines to the organization knowledge management process implementation in a selected organization.

Keywords: strategic guidelines; knowledge management; strategic knowledge management. 


\section{Introdução}

O conhecimento tem se tornado, na atualidade, um recurso cada vez mais estratégico para as organizações buscarem sua competitividade e sobrevivência: surgem, assim, as organizações baseadas no conhecimento. Mesmo no caso de setores onde a estrutura física é determinante para a atividade da organização, como é o caso dos setores de infra-estrutura, o conhecimento pode ser considerado como um recurso estratégico.

A motivação para o desenvolvimento deste trabalho apóia-se nas constatações, entre outras, de Malone (2003), em que a Gestão do Conhecimento é vista como uma potencial solução para, pelo menos, três problemas contemporâneos: uma força de trabalho em processo de envelhecimento; um crescimento geométrico na capacidade tecnológica com o respectivo aumento da quantidade de dados e informações, que estão disponíveis aos gerentes, colaboradores e demais "interessados" (stakeholders) na empresa; e uma demanda por inovação crescente nos mercados, tanto no que se refere à demanda, como também ao encurtamento do ciclo de inovação.

Para que as organizações desenvolvam uma capacidade contínua de adaptação, requerida para o desenvolvimento da sua estratégia de negócios nos dias atuais, torna-se necessária a incorporação de um enfoque fundamentado na Gestão do Conhecimento, tanto no processo de formulação da sua estratégia, como também no seu desdobramento e implementação (NONAKA e RYOKO, 2003; OKUMUS, 2003).

As organizações do conhecimento (AUGIER e KNUDSEN, 2004; KING, 2003; BROWN e DUGUID, 2001) gerenciam o conhecimento como um recurso estratégico e desenvolvem estruturas e processos para a sua organização e gestão. Adotam uma abordagem sistêmica para a Gestão do Conhecimento, desenvolvem a sua componente estratégica e utilizam as tecnologias de informação e comunicação como recursos de infra-estrutura (LEE e HONG, 2002).

O objetivo deste artigo é a construção de um framework teórico-conceitual para orientar o processo de implantação da Gestão do Conhecimento, tendo como princípio básico a sua contribuição para a realização da estratégia de negócios. Para atender tal propósito, parte-se da definição de um modelo organizacional para a Gestão do Conhecimento, para então se discutirem os principais problemas práticos da implantação da Gestão do Conhecimento nas empresas. Também compõe o escopo do trabalho o desenvolvimento de uma racionalidade de processo para a Gestão do Conhecimento, onde se incorpora a visão estratégica na forma de uma estratégia para a função Gestão do Conhecimento e de um sistema de gestão estratégica do conhecimento. O desenvolvimento da visão por processos demanda a definição, em termos metodológicos, de uma estratégia para conduzir o processo de implantação, que se desdobra dentro dos princípios da pesquisa-ação. A conclusão do trabalho é decorrente dos elementos teóricos desenvolvidos, quando se estrutura e formula um conjunto de diretrizes estratégicas. Tais diretrizes baseiam-se em um conjunto de premissas e utilizam um caso ilustrativo para compreender os aspectos relacionados ao seu conteúdo, estrutura e dinâmica.

\section{Fundamentos de um modelo organizacional}

Para se formularem as diretrizes estratégicas da Gestão do Conhecimento em uma organização, é necessário que se entenda o conhecimento como uma função empresarial. Deve-se, portanto, desenvolver um modelo organizacional para representar a mobilização da função conhecimento organizacional nos sistemas e processos organizacionais e de gestão.

A transformação da organizações em organizações do conhecimento (knowledge-based organizations) deve ser conduzida por algumas ações-chave: definindo a missão e a intenção estratégica em termos relativos à gestão do conhecimento, e representando o setor industrial da organização e o seu respectivo posicionamento nos termos da "Economia do Conhecimento" (ZACK, 2003).

King (2003) conceitua a organização que faz uso efetivo do conhecimento organizacional (Effective knowledge organization - EKO) como uma organização que cria, explica e comunica conhecimento e o aplica para desenvolver melhores processos de tomada de decisão e comportamentos organizacionais que influenciam positivamente o desempenho global da empresa.

\section{Uma EKO tem como componentes fundamentais:}

- Uma componente de aprendizagem individual que foca o desenvolvimento do capital humano através da ampliação do conhecimento individual, utilizando mecanismos como a capacitação formal em sala de aula, a educação à distância e a tutoria (formal class work, e-learning and mentoring).

- Uma componente de desenvolvimento organizacional que utiliza a aprendizagem adaptativa para criar capital social através de dispositivos que utilizam o trabalho em equipe e parcerias ou outros tipos de alianças estratégicas com empresas.

- Uma componente de gestão da propriedade intelectual que trata do conhecimento que se tenha tornado explícito, com é o caso de patentes, rela- 
tórios de pesquisa e marcas registradas, com o objetivo de gerar grandes retornos para a firma através de licenciamentos, expansão da marca e a criação de novos produtos.

- Uma componente de inovação que foca na "aprendizagem gerativa" para criar novos produtos e processos, através do pensamento criativo e que se manifesta na forma de "feiras de idéias", e pequenas subvenções financeiras para se explorar essas novas idéias.

- Uma componente de Gestão do Conhecimento que foca a explicação do conhecimento tácito que existe nas mentes das pessoas que participam da organização e daquele conhecimento que está "embutido" nos processos e relações organizacionais. Uma vez tornado explícito, tal conhecimento pode ser armazenado e comunicado através da organização.

- Uma infra-estrutura de informação/comunicação que permita a operação dessas componentes e que elas sejam integradas à estrutura de suporte para a EKO.

Augier e Knudsen (2004) estabelecem que a arquitetura e o projeto organizacional das "organizações do conhecimento" devem estar orientados ao tratamento dos problemas associados à racionalidade limitada e à exposição excessiva aos fluxos de informação.

Para Brown e Duguid (2001), as relações que se estabelecem entre organização e conhecimento devem ser estudadas na sua dimensão social e na perspectiva de sua aplicação prática. Esses autores exploram o conceito de inovação sistêmica e desenvolvem uma visão sócio-cultural para a aprendizagem e para a Gestão do Conhecimento. Emergem desses desenvolvimentos os conceitos de comunidade, redes e prática.
A Figura 1 apresenta um conjunto de relações de causa e efeito em que estratégia e desempenho são integrados por uma abordagem fundamentada na Gestão do Conhecimento (WENGER, 2004).

Uma empresa baseada em conhecimento é uma organização de aprendizagem que reconhece o conhecimento como um recurso estratégico e cria conhecimento, que pode ser processado internamente e utilizado externamente, aproveitando o potencial de seu capital intelectual, onde o trabalhador do conhecimento é o componente crítico (GARVIN, 1993). Esse conceito abrange praticamente quase todos os elementos conceituais (estratégia, estrutura, processos e pessoas) que podem ser trabalhados em um modelo de Gestão do Conhecimento.

Utilizando-se de conceitos propostos por autores como Terra (2000) e Nadler, Gerstein e Shaw (1994), além das características das empresas da "Sociedade do Conhecimento" referenciadas por Garvin (1993) e Sveiby (1997), pode-se propor um modelo de gestão para as organizações baseadas no conhecimento, tendo como fundamento quatro conceitos propostos em comum por aqueles autores, quais sejam: estratégia, estrutura, processos/tecnologia e pessoas, que serão analisados a seguir. O pressuposto é que a Gestão do Conhecimento já tenha construído elementos próprios (conceitos e práticas) que possam atender àqueles fundamentos e, neste caso, poderiam ser compreendidos como um (novo) modelo de gestão.

A Figura 2 apresenta uma taxonomia para os modelos organizacionais baseados em conhecimento. Dos modelos apresentados, observa-se que a Gestão do Conhecimento pode incorporar os seguintes componentes: processos de negócio, tecnologias de informação, repo-

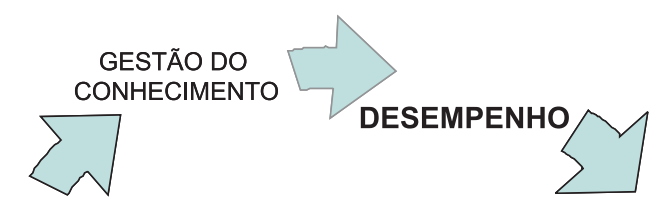

COMPARTILHAMENTO

DOMÍNIO DE

CONHECIMENTO
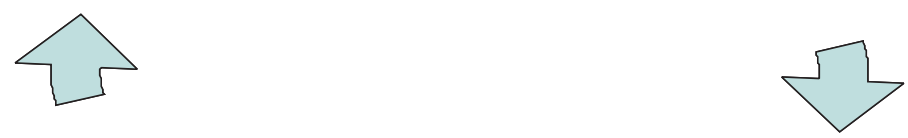

APRENDIZAGEM

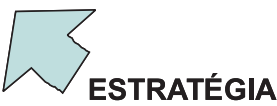

Fonte: Wenger (2004)

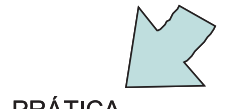

PRÁTICA

Figura 1 - Estratégia, Desempenho e Gestão do Conhecimento 




Fonte: Kakabadse, Kakabadse e Kouzmin, (2003)

Figura 2 - Modelos de gestão para o conhecimento organizacional

sitórios de conhecimento e comportamentos individuais (KAKABADSE; KAKABADSE; KOUZMIN, 2003).

Entendidos os pressupostos que fundamentam as organizações do conhecimento, podem ser estudados os principais desafios que se interpõem à sua realização.

\section{Desafios organizacionais}

A implantação de modelos organizacionais e de gestão para o conhecimento organizacional requer o desenvolvimento de "aplicações", ou seja, viabilizar a aplicação prática dos fundamentos e processos associados à Gestão do Conhecimento. O pleno desenvolvimento de uma abordagem gerencial e organizacional fundamentada na Gestão do Conhecimento tem, todavia, alguns desafios a serem superados, tanto na dimensão empresarial, como também na dimensão acadêmica.

Nota-se que o esforço contido na Gestão do Conhecimento vai desde a perspectiva da aprendizagem organizacional, que se posiciona dentro de um enfoque de natureza comportamental, até as ferramentas de gerenciamento de bases de dados que se identificam com uma abordagem orientada às tecnologias de informação e comunicação. Ruggles (1998) já estabelecia, na metade dos anos 90, um rol de aplicações para a Gestão do Conhecimento que se apresentam ainda válidas e caracterizam o momento atual das práticas implementadas pelas organizações para gerir o conhecimento organizacional. Podem-se destacar: a uso de intranets, o desenvolvimento de data warehouses e de repositórios de conhecimento, a implementação de ferramentas de apoio à decisão, a implementação de tecnologias de groupware como apoio à colaboração, o mapeamento das fontes internas de expertise, a criação de redes de trabalhadores do conhecimento e o estabelecimento de novos papéis organizacionais para tratar o conhecimento.
Holtshouse (1998) identificava para a academia alguns temas fundamentais para o desenvolvimento de uma teoria organizacional para a Gestão do Conhecimento. Para se compreender e desenvolver uma racionalidade para o processo de Gestão do Conhecimento, dever-seiam pesquisar a transferência do conhecimento tácito, o fluxo de conhecimento e a mobilização de recursos baseados em conhecimento.

Contemporaneamente a Ruggles (ibid) e Holsthouse (ibid), Teece (1998) estabelecia, como diretrizes para a academia, a intensificação dos esforços de pesquisa na quantificação de recursos intangíveis, o desenvolvimento de modelos econômicos e de natureza estratégica com o objetivo de representar e explicar as relações que se estabelecem entre os ativos tangíveis e intangíveis e o desempenho organizacional, estudar o papel das capacitações empreendedoras e administrativas em um ambiente em que se observa a convergência de tecnologias e de mercados e um ritmo acelerado de inovações.

King (2002) define a Gestão do Conhecimento como novas "aplicações" ou sistemas que utilizam a infraestrutura de tecnologia de informação existente para a criação de repositórios de conhecimento, sistemas de melhores práticas (best practices) e de lições aprendidas, redes de especialistas e comunidades de prática.

Um dos grandes desafios que se apresenta para as organizações do conhecimento é o de se transformar em uma empresa que opera em tempo real (real time enterprise). Vogels (2004) estabelece que a evolução para tal modo de operação pode seguir a seguinte trajetória, no que se refere ao desenvolvimento de capacitações: monitoramento interno e recuperação (coleta) de informação, aquisição de informação e resposta a eventos externos e abertura de seus processos em tempo real para os seus parceiros e clientes. Os 
desafios tecnológicos que se apresentam para tais empresas relacionam-se com a escala de operação da empresa em tempo real.

Atualmente, as empresas destacam uma série de desafios e de indagações no que se refere à implantação dos seus programas de Gestão do Conhecimento. King (2002), em um survey realizado com cerca de duzentas empresas, em que se entrevistaram profissionais da área de Gestão do Conhecimento e gerentes seniores, identificou, dentre vinte tópicos, os dez mais relevantes para as empresas pesquisadas. O quadro da Figura 3 apresenta estes dez tópicos na forma de questões ou desafios.

Pai (2005) aponta os seguintes temas, no formato de questões, como importantes para uma organização desenvolver uma gestão estratégica do conhecimento:

- Quais são as categorias de conhecimento que uma organização pode capturar?

- Onde uma organização captura o conhecimento de que necessita?

- Como uma organização cria continuamente ativos de conhecimento que promovem uma vantagem competitiva de longo prazo?

- Qual o conteúdo de conhecimento que uma organização deve possuir?

\begin{tabular}{|l|}
\hline \multicolumn{1}{|c|}{ Desafios para Gestão do Conhecimento } \\
\hline $\begin{array}{l}\text { 1. Como o uso da Gestão do Conhecimento pode } \\
\text { desenvolver uma vantagem estratégica (vantagem } \\
\text { competitiva)? }\end{array}$ \\
\hline $\begin{array}{l}\text { 2. Como obter o apoio da alta gerência para a Gestão } \\
\text { do Conhecimento? }\end{array}$ \\
\hline $\begin{array}{l}\text { 3. Como manter a circulação ou fluxo do conhecimento } \\
\text { organizacional? }\end{array}$ \\
\hline $\begin{array}{l}\text { 4. Como motivar as pessoas para contribuírem, através do } \\
\text { seu conhecimento individual, para um sistema de gestão } \\
\text { do conhecimento (no nível organizacional)? }\end{array}$ \\
\hline $\begin{array}{l}\text { 5. Como identificar o conhecimento organizacional que deve } \\
\text { ser capturado pelo sistema de Gestão do Conhecimento? }\end{array}$ \\
\hline $\begin{array}{l}\text { 6. Como avaliar os benefícios financeiros e custos da } \\
\text { Gestão do Conhecimento? }\end{array}$ \\
\hline $\begin{array}{l}\text { 7. Como verificar a eficácia, legitimidade e relevância } \\
\text { do conhecimento atribuído a um sistema de Gestão do } \\
\text { Conhecimento? }\end{array}$ \\
\hline $\begin{array}{l}\text { 8. Qual a melhor maneira de projetar um sistema de } \\
\text { Gestão do Conhecimento? }\end{array}$ \\
\hline $\begin{array}{l}\text { 9. Como manter de maneira sustentável os progressos } \\
\text { da Gestão do Conhecimento em uma organização? }\end{array}$ \\
\hline 10. Como garantir a proteção do conhecimento? \\
\hline Fonte: King (2002) \\
\hline
\end{tabular}

Figura 3 - Os 10 grandes desafios para a Gestão do Conhecimento
- Como uma organização armazena e replica o seu conhecimento em rotinas?

- Como uma organização protege o seu conhecimento?

- Os ativos de conhecimento de uma organização são relevantes para sustentar a sua vantagem competitiva?

Essas questões identificam a necessidade de se trabalhar com o conhecimento categorizando-o, definindo suas fontes, compreendendo e gerindo seu processo de criação, identificando o seu conteúdo, integrando-o às capacitações, competências e processos organizacionais e de gestão, implementando políticas para a sua proteção.

Há também na literatura uma série de estudos que buscam identificar os fatores que influenciam na adoção de um sistema para a Gestão do Conhecimento. Hung et al. (2005) e Wong (2005) apresentam uma lista de tais fatores, que segue apresentada no quadro da Figura 4 .

Estabelece-se, portanto, um domínio de aplicação para a Gestão do Conhecimento, elegem-se as áreas de interesse acadêmico e formulam-se desafios e identificamse os elementos que devem compor o planejamento da adoção da Gestão do Conhecimento nas empresas. De posse desses elementos, pode-se organizar uma racionalidade para a implantação da Gestão do Conhecimento através de um processo.

\section{0 processo corporativo de Gestão do Conhecimento}

A Gestão do Conhecimento requer um contexto organizacional apropriado. Há necessidade de processos para coordenar a Gestão do Conhecimento e integrá-la aos processos de negócio. Tais processos se estabelecem através das tecnologias para coordenar os fluxos de informação, das conexões interpessoais, dos repositórios de documentos e também pelas normas institucionais e culturais orientadas à Gestão do Conhecimento organizacional (WENGER, 2004).

A Gestão do Conhecimento, entendida na medida de seus processos, desenvolve-se nos seguintes níveis de intervenção: da estratégia para o conhecimento organizacional, de seu conteúdo e estrutura, de seus instrumentos/ferramentas/práticas e sistemas e de seus processos organizacionais e de gestão (MAIER e REMUS, 2003).

Para Maier e Remus (2003), dois modelos podem ser considerados na implantação da Gestão do Conhecimento voltada a processos (PKM - Process-oriented Knowledge Management):

- As iniciativas de gestão por processo são conduzidas por uma unidade ou por um projeto específico e podem resultar em uma abordagem voltada à 


\begin{tabular}{|l|l|}
\hline \multicolumn{1}{|c|}{$\begin{array}{c}\text { Fatores que afetam a adoção da Gestão do } \\
\text { Conhecimento segundo Hung et al. (2005) }\end{array}$} & \multicolumn{1}{|c|}{$\begin{array}{c}\text { Fatores críticos de sucesso na implementação da } \\
\text { Gestão do Conhecimento segundo Wong (2005) }\end{array}$} \\
\hline $\begin{array}{l}\text { Uma cultura organizacional aberta e de confiança. } \\
\text { Liderança e comprometimento da alta direção. } \\
\text { Envolvimento (comprometimento) dos colaboradores. }\end{array}$ & $\begin{array}{l}\text { Gestão da liderança e apoio (liderança e suporte). } \\
\text { Cultura. } \\
\text { Treinamento (capacitação) dos colaboradores. }\end{array}$ \\
Tredibilidade e confiança no trabalho em equipe. & Estratégia e propósito (missão, valores e visão). \\
Empowerment (autonomia) dos colaboradores. & Medição. \\
Infra-estrutura dos sistemas de informação. & Infra-estrutura organizacional. \\
Medição de desempenho. & Processos e atividades. \\
Benchmarking. & Apoio motivacional. \\
Estrutura de Conhecimento (Base de Conhecimento). & Recursos. \\
\hline
\end{tabular}

Fonte: Hung et al. (2005) e Wong (2005)

Figura 4 - Fatores que afetam a adoção da Gestão do Conhecimento

Gestão do Conhecimento (e.g. modelagem dos processos de negócio).

- Um projeto de Gestão do Conhecimento com um forte foco em processos de negócio que sejam intensivos em conhecimento (e.g. Portais Corporativos). Esta é uma abordagem orientada à tecnologia.

Para conceber uma visão por processo para a Gestão do Conhecimento, Lee e Hong (2002) desenvolvem o conceito de ciclo de vida para a Gestão do Conhecimento: captura de conhecimento, desenvolvimento de conhecimento, compartilhamento de conhecimento e utilização do conhecimento. O quadro da Figura 5 descreve tal abordagem para a Gestão do Conhecimento.

Para desenvolver uma visão de processo para a Gestão do Conhecimento, Verkasalo e Lappalainen (1998) conceituam o "domínio de conhecimento" como um ambiente em que uma nova idéia, pensamento ou informação é "relacionada/associada" e avaliada. O domínio de conhecimento se estabelece, estando disponível, no nível de um indivíduo ou grupo. Para os autores, a Gestão do Conhecimento se materializa

\begin{tabular}{|l|l|}
\hline Etapas do Ciclo de Vida & \multicolumn{1}{|c|}{$\begin{array}{c}\text { Tecnologias de Informação } \\
\text { e Comunicação }\end{array}$} \\
\hline Captura do Conhecimento & $\begin{array}{l}\text { Sistemas de Banco de Dados } \\
\text { Data Warehouse } \\
\text { Biblioteca Digital }\end{array}$ \\
\hline $\begin{array}{l}\text { Desenvolvimento } \\
\text { do Conhecimento }\end{array}$ & $\begin{array}{l}\text { Data mining } \\
\text { OLAP (On Line Analytical Process) } \\
\text { Sistemas de inteligência competitiva }\end{array}$ \\
\hline $\begin{array}{l}\text { Compartilhamento } \\
\text { do Conhecimento }\end{array}$ & $\begin{array}{l}\text { Sistemas corporativos que utilizem } \\
\text { tecnologia de grupo } \\
\text { Intranet (www) }\end{array}$ \\
\hline Utilização do Conhecimento & $\begin{array}{l}\text { GUI (Graphical User Interface) - } \\
\text { interfaces gráficas } \\
\text { Tecnologias multimídia }\end{array}$ \\
\hline
\end{tabular}

Figura 5 - Ciclo de vida do conhecimento organizacional através do processo de utilização do conhecimento, que se organiza nas seguintes fases:

- Aquisição da informação;

- Documentação;

- Transmissão de informação e de conhecimento;

- Recebimento da informação;

- Percepção do conhecimento;

- Tomada de decisão.

Muito do que se estuda atualmente em Gestão do Conhecimento relaciona-se com os processos de transferência e difusão do conhecimento. Amesse e Cohendet (2001), apropriando-se da racionalidade dos processos de transferência de tecnologia, estabelecem que estes podem ser essencialmente vistos como um processo de transferência de conhecimento que depende de como as empresas e outras instituições abordam o conhecimento, particularmente associada à co-evolução das suas capacidades de absorção (COHEN e LEVINTHAL, 1990) e das suas estratégias de difusão/transmissão do conhecimento.

A abordagem por processo, quando aplicada à Gestão do Conhecimento, pode também resultar nos estudos dos processos de aprendizagem organizacional, relacionando à criação ou apropriação de conhecimento e os seus respectivos mecanismos de difusão ou transmissão, estar-se-ia estudando o "conhecimento em ação" (ARGYRIS, 1993). Estudar os processos associados ao conhecimento organizacional através da aprendizagem pode levar ao estudo da aprendizagem tecnológica (FLEURY

e FLEURY, 1997). Carayannis (1999) caracteriza a aprendizagem tecnológica em quatro níveis: operacional, tático, estratégico e meta-estratégico; e de quatro tipos: individual, intra-organizacional, interorganizacional e supra-organizacional. 
Para Kim, Yu e Lee (2003), os processos de Gestão do Conhecimento podem ser sumarizados em criação/ aquisição; registro (codificação e classificação)/armazenamento, compartilhamento/utilização e atualização/ conclusão.

Wiig (1999) desenvolve uma visão sistêmica para a Gestão do Conhecimento em uma organização. A Figura 6 representa tal visão, destacando as interfaces e sombreamentos que um processo empresarial para a Gestão do Conhecimento estabelece com a gestão de recursos humanos, com a pesquisa e desenvolvimento e com os sistemas e tecnologias da informação e comunicação.

Para Harrington (1993) e Bueno (1997), um processo contém funções ou atividades que se inter-relacionam, visando a um resultado comum. No contexto do modelo de GC a ser apresentado, tais atividades são denominadas de "práticas de Gestão do Conhecimento". O processo de GC tem como componentes "funções" que, segundo vários autores pesquisados (DAVENPORT,
1998; BECKMAN, 1999), incluem a identificação, a captura, a seleção e validação, a organização e armazenagem, o compartilhamento (acesso e distribuição), a aplicação e a criação do conhecimento.

A arquitetura de Gestão do Conhecimento contribui para a estruturação da Gestão do Conhecimento como função e fundamenta-se na classificação do conhecimento organizacional, nos processos de Gestão do Conhecimento, na estrutura organizacional e no sistema/tecnologia de informação (KIM, YU e LEE, 2003).

As Práticas de Gestão do Conhecimento permeiam uma ou mais das funções acima e visam a operacionalizar os processos de Gestão do Conhecimento. Não há consenso entre os autores sobre essas práticas: assim, de acordo com pesquisas na literatura e evolução dos conceitos, foram definidas cinco práticas: Aprendizagem Organizacional, Gestão de Competências, Gestão do Capital Intelectual, Educação Corporativa, Inteligência Empresarial.

\section{Processo Empresarial de Gestão do Conhecimento}

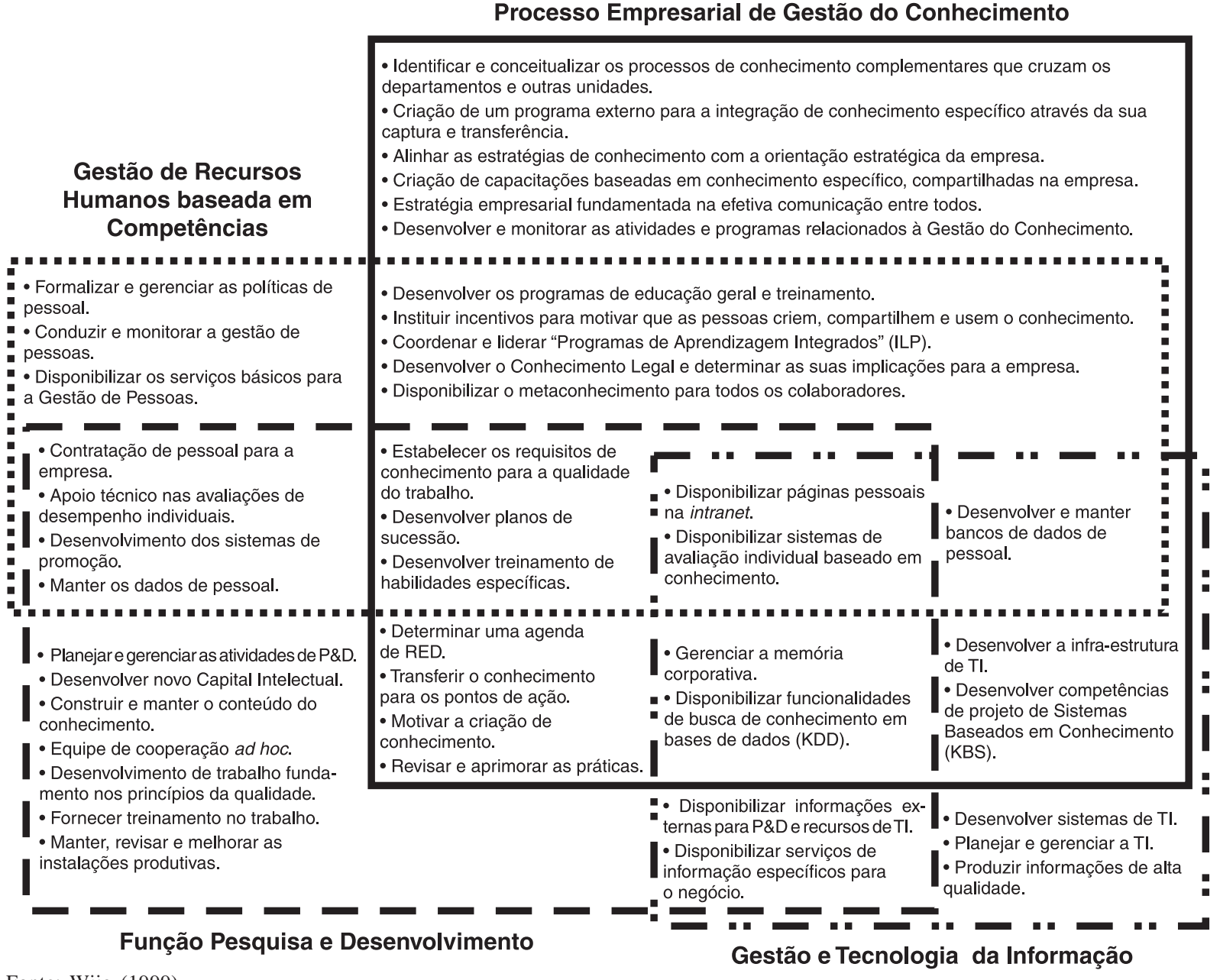

Fonte: Wiig (1999) 
O modelo proposto neste trabalho, para a gestão das organizações baseadas no conhecimento, pode ser considerado um novo modelo organizacional, pois atende às características assinaladas por Nadler, Gerstein e Shaw (1994) e Terra (1999), em suas respectivas propostas de arquitetura organizacional e de modelo de Gestão do Conhecimento.

A Figura 7 organiza, em um framework orientativo para a implantação de um processo corporativo de Gestão do Conhecimento, as dimensões, funções e práticas relativas à Gestão do Conhecimento em uma organização.

Para operacionalizar tal framework, e garantir o seu alinhamento com a estratégia de negócios da empresa, é necessária a criação de um conjunto de diretrizes orientadoras fundamentadas em uma "estratégia para o conhecimento organizacional".

\section{A dimensão estratégica da Gestão do Conhecimento}

O desempenho superior de uma estratégia é contingente ao quão bem um conjunto de políticas e práticas está alinhado aos requisitos ou determinantes dessa estratégia (OLSON, SLATER e HULT, 2005). É justamente dentro desta perspectiva que se desenvolverá uma abordagem de natureza estratégica para a Gestão do Conhecimento.

Snyman e Kruger (2004) destacam a importância estratégica do conhecimento e da informação. Fundamentamse na base do conhecimento organizacional e no seu desenvolvimento, bem como no fluxo do conhecimento, para gerar a estratégia de negócios.
Zack (2005) distingue a Estratégia de Gestão do Conhecimento e a Gestão Estratégica do Conhecimento. A Estratégia de Gestão do Conhecimento implica em uma estratégia baseada no conhecimento, ou seja, uma estratégia competitiva formulada a partir de seus recursos e capacitações intelectuais. A Gestão Estratégica do Conhecimento concebe e define os processos e infraestruturas para a Gestão do Conhecimento.

A criação de conhecimento pode ser concebida como um processo dialético. Nesse sentido, o papel da estratégia é o de adaptar a organização ao seu meio, bem como o de mobilizar seus recursos (NONAKA e RYOKO, 2003).

Segundo April (2002), o uso de uma abordagem baseada em recursos e capacitações é fundamental para o desenvolvimento de uma estratégia de Gestão do Conhecimento, ou seja, uma estratégia empresarial fundamentada no conhecimento. Para Smith (2004), a estratégia de Gestão do Conhecimento deve refletir a estratégia competitiva da empresa. Os esforços para codificação do conhecimento caracterizam a orientação central das estratégias de Gestão do Conhecimento. Fundamentam-se no intensivo uso das tecnologias de informação e comunicação e promovem substanciais ganhos de produtividade e de satisfação de seus usuários (SMITH, 2004).

O uso estratégico do conhecimento pode ser tratado na perspectiva de uma estratégia baseada na informação ou na perspectiva de uma estratégia baseada no conhecimento. O quadro da Figura 8 apresenta as principais características dessas duas abordagens e serve de referência para que as empresas se posicionem em relação ao tratamento estratégico a ser dado à Gestão do Conhecimento (SVEIBY, 1997).

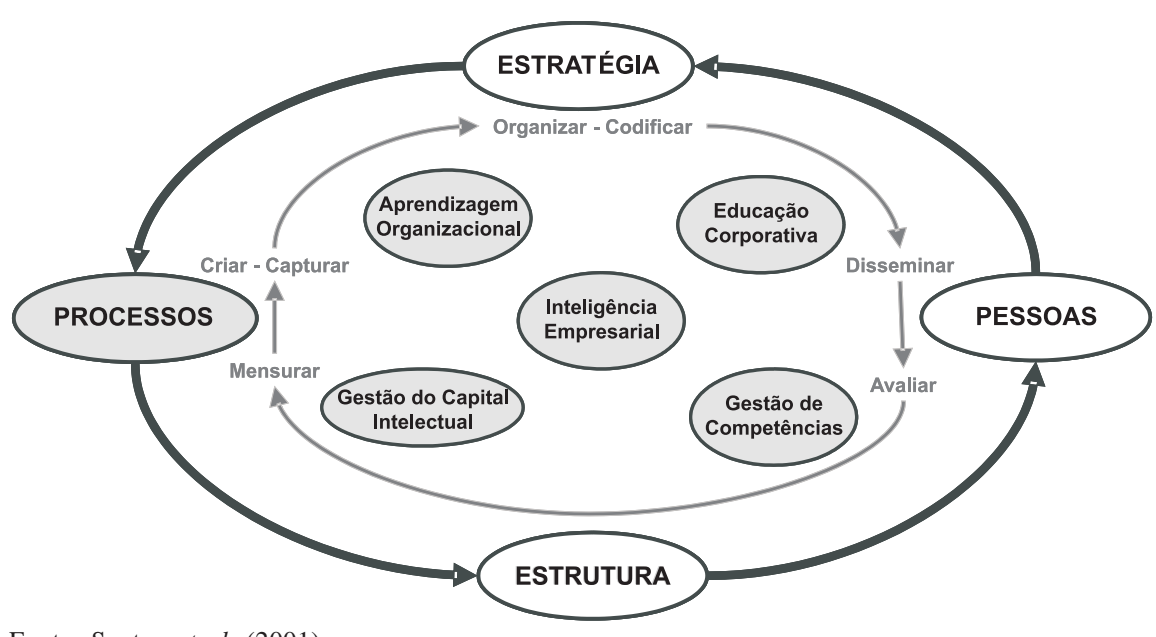

Fonte: Santos et al. (2001)

Figura 7 - Modelo de referência para a gestão do conhecimento 


\begin{tabular}{|l|l|}
\hline \multicolumn{1}{|c|}{$\begin{array}{c}\text { Estratégia baseada em } \\
\text { informação }\end{array}$} & \multicolumn{1}{|c|}{$\begin{array}{c}\text { Estratégia baseada em } \\
\text { conhecimento }\end{array}$} \\
\hline Baixo grau de customização & Alto grau de customização \\
\hline $\begin{array}{l}\text { O conhecimento transa- } \\
\text { cionado como subproduto }\end{array}$ & $\begin{array}{l}\text { O conhecimento transa- } \\
\text { cionado como um processo }\end{array}$ \\
\hline $\begin{array}{l}\text { Retornos crescentes com } \\
\text { a eficiência }\end{array}$ & $\begin{array}{l}\text { Retornos crescentes com } \\
\text { a eficácia }\end{array}$ \\
\hline $\begin{array}{l}\text { Economia de escala como } \\
\text { vantagem na produção }\end{array}$ & $\begin{array}{l}\text { Desvantagens com a } \\
\text { economia de escala }\end{array}$ \\
\hline $\begin{array}{l}\text { Grandes volumes e } \\
\text { mercados de massa }\end{array}$ & $\begin{array}{l}\text { Pequenos volumes } \\
\text { e clientes individuais }\end{array}$ \\
\hline $\begin{array}{l}\text { Investimento em tecnologia } \\
\text { computacional }\end{array}$ & Investimento em pessoas \\
\hline Pessoas como "custos" & Competências individuais \\
\hline Fonte: Sveiby (1997)
\end{tabular}

Figura 8 - Concepção de estratégia para o conhecimento organizacional

Também a esta dimensão estratégica da Gestão do Conhecimento podem ser relacionados processos: um processo organizacional e um processo de gestão.

O processo organizacional descreve o planejamento e a estruturação da Gestão do Conhecimento em uma empresa. Materializa-se através das funções associadas à Gestão do Conhecimento.

O processo de gestão se dá na dimensão da gestão estratégica do conhecimento e tem o papel de coordenar a realização da função "conhecimento". Desenvolve-se para essa finalidade todo um conjunto de ferramentas para o planejamento e avaliação dos resultados ou do desempenho da Gestão do Conhecimento.

Kim, Yu e Lee (2003) propõem uma metodologia para o planejamento estratégico da Gestão do Conhecimento que se fundamenta no desempenho organizacional e na visão por processos (Performance driven and processbased knowledge strategy planning methodology: P2KSP). Essa metodologia desenvolve-se em cinco fases:

- $1^{\mathrm{a}}$ fase: Análise do ambiente de negócios.

- $2^{\mathrm{a}}$ fase: Análise dos requerimentos de conhecimento.

- $\quad 3^{\text {a }}$ fase: Estabelecimento da estratégia de Gestão do Conhecimento.

- $4^{\mathrm{a}}$ fase: Projeto da "arquitetura" para a Gestão do Conhecimento.

- $5^{\mathrm{a}}$ fase: Planejamento da implantação da Gestão do Conhecimento.

As estratégias de Gestão do Conhecimento devem ser capazes de contribuir para a melhoria da eficiência e da efetividade dos processos de negócios, e, finalmente, para o desempenho organizacional. A Gestão do Conhecimento deve ser vista como abordagem integrada que compreende aspectos administrativos, culturais e técnicos de uma organização. Uma metodologia para o planejamento da estratégia de conhecimento permite à organização identificar os seus conhecimentos essenciais (core knowledge) e projetar a infra-estrutura organizacional para a sua gestão. A infra-estrutura organizacional é a base para fundamentar os aspectos humanos, organizacionais, administrativos, culturais e técnicos da Gestão do Conhecimento. A visão do sistema organizacional, vinculada aos indicadores de desempenho definidos no nível empresarial, e a visão dos processos organizacionais, cuja análise é um pré-requisito para a identificação do conhecimento organizacional (particularmente, os conhecimentos críticos), são condições necessárias para a formulação de estratégias e também para a sua gestão (KIM, YU e LEE, 2003). Destaca-se, portanto, na gestão estratégica do conhecimento, o desenvolvimento de sistemas especializados de medição de desempenho. Del Rey Chamorro et al. (2003) apresentam um framework para a criação de indicadores-chave de desempenho para a Gestão do Conhecimento que se desenvolvem em dois níveis: para medir o desempenho da solução implementada e para monitorar a adequação da solução adotada aos objetivos estratégicos de negócio.

Gooijer (2000) considera como áreas-chave para a concepção de um sistema de medição para a Gestão do Conhecimento:

- Estratégia.

- Produtos e serviços.

- Infra-estrutura de informação (tecnologia e conteúdo).

- Processos.

- Relações institucionais.

- Cultura e comportamento.

Wiig (1999) desenvolve uma racionalidade para a gestão estratégica do conhecimento, em que se representam as relações de causa-efeito que se verificam entre as atividades de Gestão do Conhecimento e o desempenho organizacional. A Figura 9 apresenta tal racionalidade.

Neste ponto da construção teórica desenvolvida, observa-se a articulação dos seguintes elementos: um modelo de gestão para o conhecimento organizacional, um processo empresarial para a Gestão do Conhecimento e o desenvolvimento de uma visão estratégica para a Gestão do Conhecimento. Apresentaram-se, também, o escopo de aplicação e os principais desafios que apresentam às empresas e à academia no que se refere à Gestão do Conhecimento. Para com- 


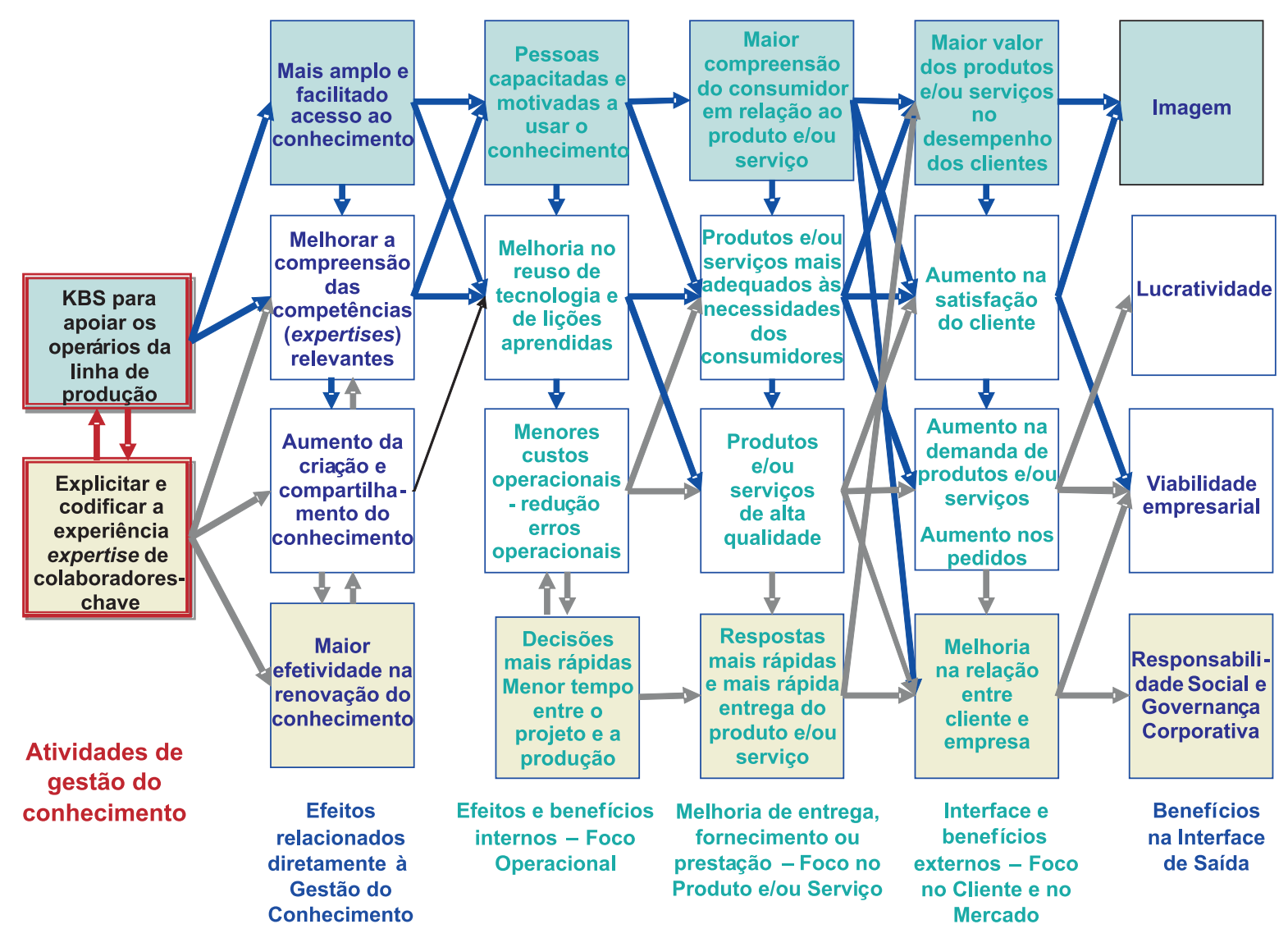

Fonte: Wiig (1999)

Efeitos e benefícios intermedíarios

Figura 9 - O desempenho organizacional e as atividades de Gestão do Conhecimento

pletar o desenvolvimento deste trabalho, serão apresentados dois elementos que conformarão os conceitos teóricos desenvolvidos: uma abordagem metodológica para a condução de projetos de implantação de Gestão do Conhecimento e a síntese de um conjunto de diretrizes estratégicas para a implantação da Gestão do Conhecimento.

\section{A abordagem metodológica}

Para o desenvolvimento e criação das diretrizes estratégicas para a implantação da Gestão do Conhecimento, propõe-se a utilização de um processo participativo process approach - em que técnicas como pesquisa-ação, sondagem eletrônica, entrevistas, análise documental e observação direta são aplicadas e gerenciadas em um modelo de "projeto de pesquisa". Sob o ponto de vista organizacional, o processo é conduzido por um grupo de trabalho composto por membros da organização estudada e uma equipe de especialistas.

Coughlan e Coghlan (2002) chamam a atenção para o fato de que os resultados desejados da pesquisa-ação não são apenas as soluções para o problema imediato sob investigação, mas também o importante aprendizado sobre os resultados pretendidos e "não pretendidos", e uma contribuição à teoria e ao conhecimento científico. Este aspecto está presente na condução do processo e produz comunicação e aprendizagem coletivas.

O processo de concepção das diretrizes estratégicas para a implantação da Gestão do Conhecimento busca "gerar conhecimento para a ação". O que se procura é transformar conhecimento em ação através da modificação das teorias em uso e dos modelos utilizados no sistema social. Observa-se que esta perspectiva se vincula a um tipo de pesquisa ou de intervenção baseado na resolução de problemas, e o conhecimento é gerado e experimentado, validado e justificado ao longo do processo, ou seja, "em ação". Praticamente, este tipo de abordagem se identifica com a construção de estratégias, em diferentes níveis, de políticas, rotinas e culturas que são a finalidade da implantação da Gestão do Conhecimento e o seu alinhamento com a estratégia empresarial (ARGYRIS, 1993).

Para Platts et al. (1996), um processo "é uma seqüência de eventos que descreve como as coisas se modificam ao longo do tempo". Um processo é usualmente desenvolvido com algum objetivo em mente (PLATTS et al., 
1998). O propósito pode ser implícito ou explícito (e.g. desenvolver habilidades e cultura de "times").

Assim, a abordagem por processo tem como motivação o desenvolvimento de uma abordagem prescritiva, que operacionaliza um conjunto de conceitos, através de um processo estruturado.

Platts (1993) ressalta que "é preciso reconhecer claramente que este tipo de pesquisa [que adota a abordagem por processo] não objetiva o desenvolvimento de uma teoria descritiva, mas o desenvolvimento de processos que irão operacionalizar frameworks existentes e prover as empresas de abordagens práticas para a melhoria de suas operações".

No que se refere à instrumentalização de conceitos, a metodologia cria uma sequiência de fases, sendo cada fase composta por passos. A coleta de dados se dá num processo dinâmico de pesquisa-ação, que emprega folhas de tarefa (worksheets) que "são usadas para capturar informação", além de que várias ferramentas de visualização podem ser empregadas (como flip-charts ou os mapas estratégicos, descritos em Mills et al., 1998).

Em Platts (1994) e Platts et al. (1998), encontra-se que, para ser efetivo, um processo deve ter os seguintes elementos:

- Procedimentos (expor os passos lógicos do processo).

- Participação (garantir o envolvimento dos atoreschave).

- Gestão do Projeto (garantir que o processo contará com os recursos necessários e que terá andamento de acordo com um plano definido).

- Ponto de Entrada (forma de apresentar o processo e obter comprometimento).

O processo de concepção das diretrizes tem como "entradas" um diagnóstico empresarial e uma pesquisa de campo que levanta dados e informações relativos ao estado atual da Gestão do Conhecimento na empresa, utilizando como evidências documentos e relatórios, entrevistas com o corpo técnico e gerencial, visitas técnicas e uma sondagem eletrônica. Esses procedimentos são organizados e sistematizados através do process approach. O resultado é a construção de um conjunto de premissas básicas e de um conjunto de declarações que descrevem as diretrizes estratégicas para a implantação da Gestão do Conhecimento.

Destaca-se, dentre as técnicas utilizadas para a identificação das práticas existentes de Gestão do Conhecimento, a aplicação da sondagem eletrônica (KLASSEN e JACOBS, 2001; FROHLICH, 2002). $\mathrm{O}$ instrumento de pesquisa, desenvolvido para a sondagem, é composto por 87 questões, divididas em 10 sub-temas: Estratégia Funcional; Recursos, Capacitações e Competências; Gestão de Competências Individuais; Aprendizagem Organizacional; Educação Corporativa; Gestão do Capital Intelectual (de Relacionamento, Estrutural e Humano); Inteligência Empresarial; Tecnologias de Informação e Comunicação. Para o desenvolvimento e aplicação da sondagem foi concebida uma plataforma aberta baseada em Web, utilizando linguagem PHP e um banco de dados MySQL (software livre).

A Figura 10 apresenta uma sistematização das etapas que apóiam o processo metodológico desenvolvido para a geração das diretrizes estratégicas para a Gestão do Conhecimento. Destacam-se a análise estratégica, o mapeamento das práticas existentes, o processo participativo e sistemático para a concepção das diretrizes e a utilização de procedimentos para refinamento e validação do processo.

A concepção de um plano de implantação para um processo empresarial ou corporativo de Gestão do Conhecimento deve garantir o seu alinhamento com a estratégia da empresa. Sendo assim, as diretrizes que orientam a formulação de tal plano devem garantir o alinhamento desejado. A metodologia proposta fundamenta-se na concepção de um conjunto de diretrizes estratégicas para orientar a formulação de um plano de implantação da Gestão do Conhecimento. O produto deste processo é a formulação de um conjunto de diretrizes estratégicas.

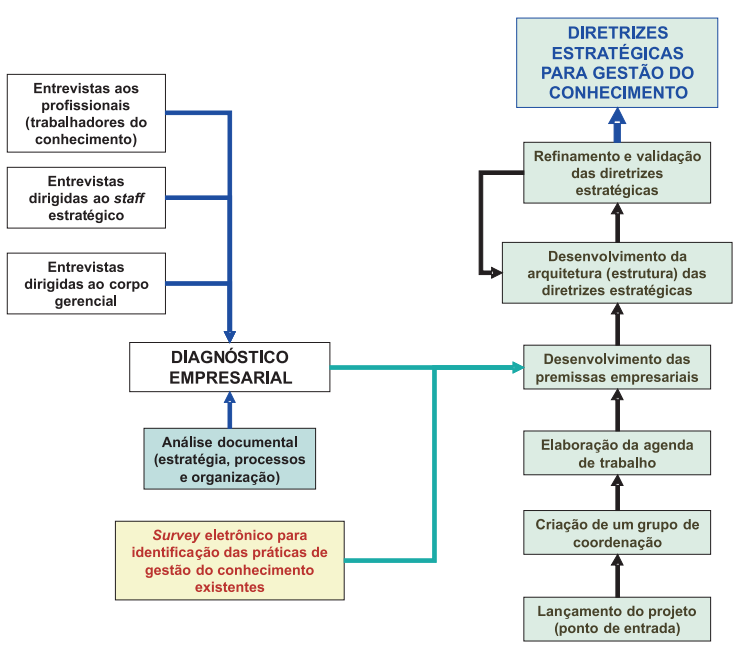

Figura 10 - O processo metodológico 


\section{A formulação das diretrizes estratégicas}

As diretrizes estratégicas para a implantação da Gestão do Conhecimento têm caráter orientativo e devem antecipar-se aos problemas típicos de implantação e garantir a coerência estratégica.

Diretrizes estratégicas são elementos orientadores que fundamentam a elaboração de políticas, programas e projetos para a realização da estratégia empresarial. Para a elaboração das diretrizes deve-se, previamente, estabelecer um conjunto de premissas, onde se determinam as condições necessárias para a implantação de um processo empresarial de natureza corporativa para a Gestão do Conhecimento. Tais premissas definem o posicionamento da empresa em relação à adoção de práticas de Gestão do Conhecimento. As premissas referem-se a aspectos conceituais (teóricos) e empresariais ou corporativos (específicos da empresa), conforme ilustrado pelo quadro da Figura 11.

A elaboração das premissas fundamenta-se no processo de Gestão do Conhecimento da Empresa, que tem uma natureza corporativa e interdisciplinar, e deve desenvol- ver interfaces com as diferentes funções e processos organizacionais e de gestão existentes.

Na Figura 12, Lin e Tseng (2005) relacionam e representam os principais pontos críticos (gaps) a serem observados na implantação da Gestão do Conhecimento em uma empresa.

O gap 1 apresenta-se como um gap de percepção, enquanto que os gaps 2 e 3 referem-se aos processos de implantação da Gestão do Conhecimento propriamente dita. O gap 4 está associado à efetividade da implantação do sistema de Gestão do Conhecimento. Os gaps 5 e 6 trabalham o nível de compreensão e de percepção dos colaboradores da empresa em relação ao conhecimento necessário para se desenvolver uma operação sustentável. Tais gaps são superados através de uma gestão estratégica do conhecimento. As diretrizes estratégicas para a implantação da Gestão do Conhecimento em uma empresa têm como objetivo o tratamento desses gaps para que se tenha uma efetiva Gestão do Conhecimento organizacional (LIN e TSENG, 2005).

Dadas as premissas: o referencial teórico expresso através do modelo da Figura 7, a aplicação do diagnóstico para identificação dos requisitos estratégicos, para

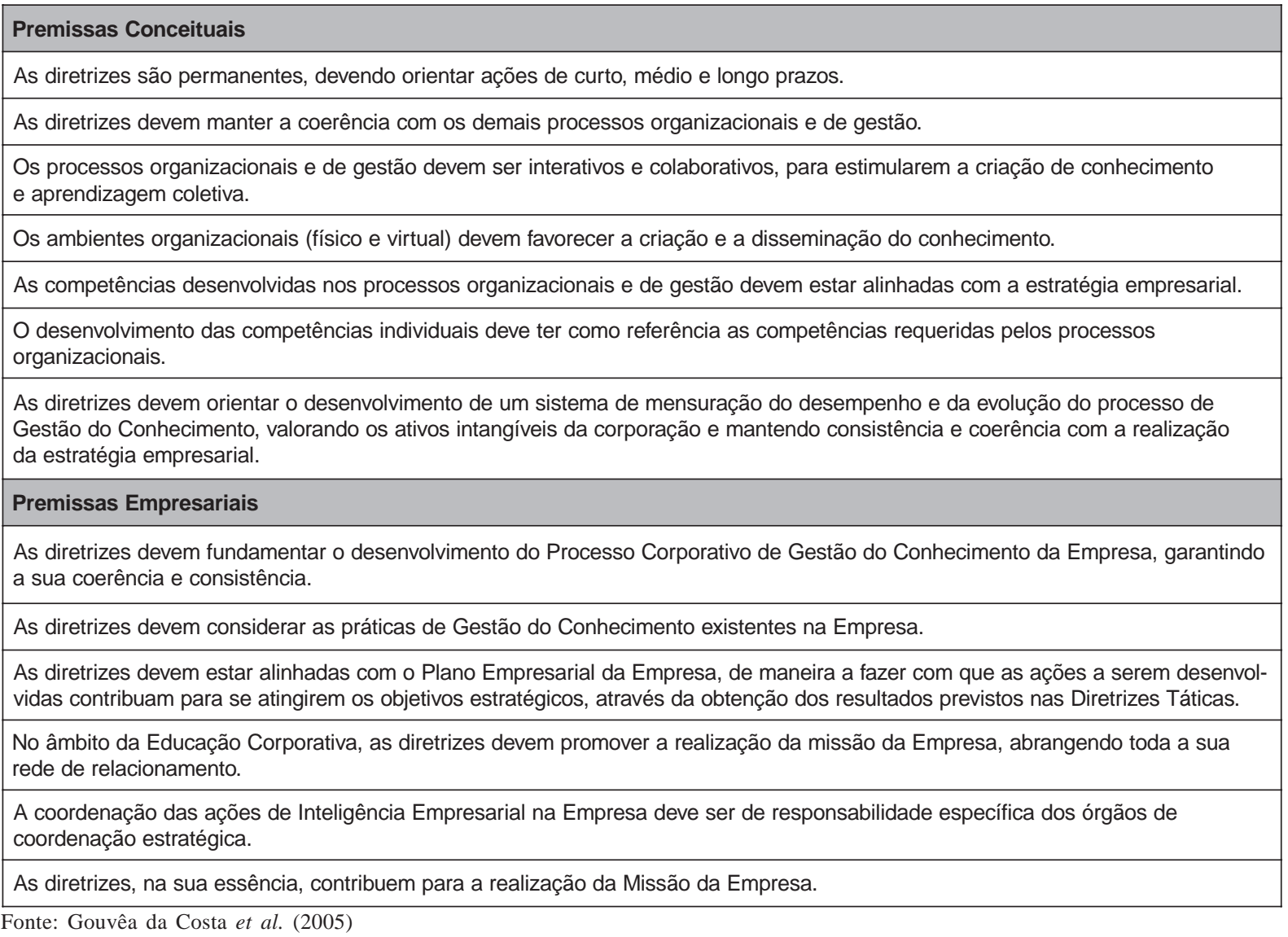




\section{Ambiente externo da empresa}

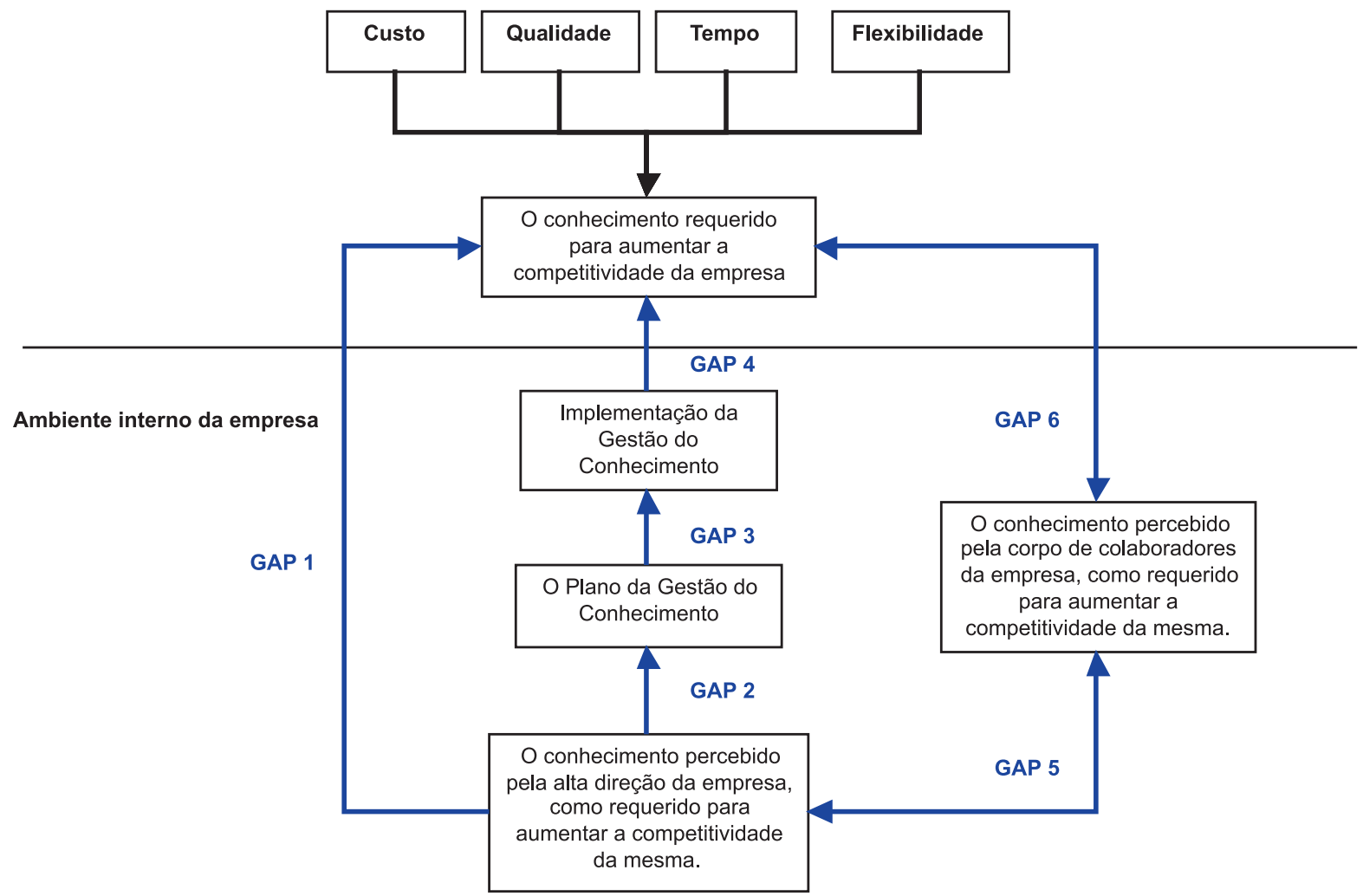

Fonte: Lin e Tseng (2005)

Figura 12 - Pontos críticos para a implantação da Gestão do Conhecimento

levantamento das práticas existentes de Gestão do Conhecimento e da percepção dos colaboradores da empresa em relação à Gestão do Conhecimento, podemse formular as diretrizes estratégicas. O processo de formulação é participativo, sistemático, permite a aprendizagem e a difusão dos modelos, processos e estruturas desenvolvidos. O resultado permite a categorização das diretrizes e o estabelecimento de um framework integrativo. A Figura 13 ilustra tal agrupamento, indicando as relações de causa e efeito.

Para ilustrar esse processo de formulação, apresentamse os resultados da aplicação em uma empresa de infra-

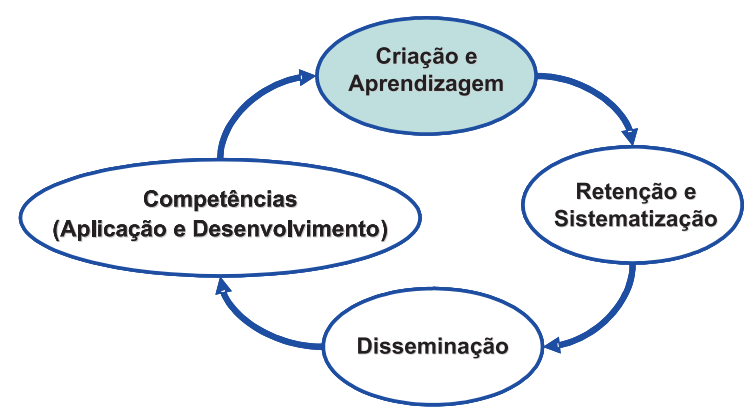

Fonte: Gouvêa da Costa et al. (2005)

Figura 13 - Lógica de relacionamento das diretrizes estrutura. As diretrizes foram organizadas em quatro grandes categorias: criação do conhecimento e aprendizagem organizacional, retenção e sistematização de conhecimento, disseminação de conhecimento e desenvolvimento de competências. Essas categorias evidenciam os principais problemas e desafios identificados para a implantação de um processo empresarial ou corporativo de Gestão do Conhecimento na Empresa " $X$ ". A organização das diretrizes em categorias é regida pela lógica apresentada na Figura 13.

Entende-se que a origem do processo se dá na criação de conhecimento ou no processo de aprendizagem organizacional. O conhecimento gerado nesses processos deve ser retido e sistematizado para a sua futura disseminação. A aplicação do conhecimento se dá através das competências organizacionais e individuais que são mobilizadas em diferentes processos dentro da organização. Como as competências estão em constante desenvolvimento, provocam um processo de contínua aprendizagem, observado no círculo virtuoso da Figura 12.

Para Fleury e Fleury (1997), a aprendizagem pode se desenvolver nas perspectivas de aprender ao operar (learning by operating), ao mudar (learning by changing), pela análise do desempenho (system performance feedback), ao treinar (learning through training), por 
contratação (learning by hiring) e por busca (learning by searching). Senge (1990) desenvolve uma visão sistêmica e integrada para a aprendizagem organizacional.

A retenção e sistematização do conhecimento organizacional podem ser trabalhadas dentro de uma perspectiva de apoio aos sistemas organizacionais e, então, se incorporariam aos sistemas computacionais de apoio, integrados às bases de conhecimento (computer-assisted knowledge system), sendo estas vistas como repositórios de conhecimento. São exemplos dessa segunda forma de aplicação das bases de conhecimento os data warehouse, os sistemas de informação gerencial, sistemas de apoio à decisão, sistemas de gestão integrada, entre outros. Nessa perspectiva, destacam-se aspectos como a integração e sistematização das bases de dados, informação e conhecimento. Também, algumas metodologias vêm sendo desenvolvidas com vistas à integração dos sistemas voltados à Gestão do Conhecimento, como a CommonKADS (knowledge acquisition and design support), que contribui com o projeto e implantação de sistemas baseados em conhecimento, e também para o seu processo de integração em diferentes níveis e funções (DE HOOG, 1997 e SOR, 2004).

A dimensão da disseminação pode ser entendida via tecnologias de informação e de comunicação; no entanto, a visão do processo de criação do conhecimento de Nonoka e Takeuchi (1997), e dos espaços para a criação de conhecimento de Nonaka e Konno (1998), explicam de maneira mais completa a disseminação de conhecimento. $\mathrm{O}$ futuro papel das tecnologias de informação e comunicação, na Gestão do Conhecimento, é o da integração do conhecimento organizacional via intranet e o desenvolvimento de sistemas corporativos para a Gestão do Conhecimento (LEE e HONG, 2002).

O ciclo se encerra na criação e desenvolvimento de competências (BUENO, 1998), que representam o conhecimento em ação (ARGYRIS, 1993) e os diferentes tipos e níveis de competências a serem desenvolvidas na organização (PINHEIRO DE LIMA e LEZANA, 1999).

Pode-se, de acordo com Sanchez e Heene (1997), tratar as competências através de quatro conjuntos de propriedades: as dinâmicas, as sistêmicas, as cognitivas e as "holísticas", e associá-las aos conceitos de recursos, capacitações, habilidades, objetivos e conhecimento, para se trabalhar dentro das perspectivas de:

- integrar os processos organizacionais e dotação de recursos;

- integrar as estruturas da organização industrial e a dinâmica da mudança;

- integrar os processos cooperativos e competitivos;
- definir a natureza dos papéis críticos relacionados aos processos cognitivos e de coordenação;

- identificar as interdependências sistêmicas que compõem as competências organizacionais;

- justificar o crescente uso de alianças e redes;

- destacar o papel da aprendizagem como crítico na identificação, construção e alavancagem de competências;

- integrar os diferentes propósitos dos sistemas sociais que extrapolam a perspectiva "utilitária".

O quadro da Figura 14 apresenta algumas das diretrizes estratégicas desenvolvidas no caso estudado.

Apresentados os fundamentos para a elaboração das diretrizes estratégicas para a implantação da Gestão do Conhecimento em uma empresa, podem-se tecer algumas considerações finais.

Criação do Conhecimento e Aprendizagem Organizacional

O processo de prospecção de informações na Empresa " $X$ " deve se desenvolver tanto interna quanto externamente, envolvendo a identificação de fontes de informação e o monitoramento de tecnologias, mercados e do setor público.

As relações da Empresa " $X$ " com o seu ambiente externo devem propiciar e/ou estimular a busca contínua de novos conhecimentos que criem valor para a Entidade, considerando o seu caráter de interesse público.

Retenção e Sistematização do Conhecimento

As informações geradas e coletadas pela Empresa " $X$ " devem ser organizadas, mantidas e disponibilizadas por intermédio de sistemas corporativos.

O conhecimento de natureza tecnológica da Empresa "X" deve ser gerenciado como um recurso para promover o desenvolvimento econômico sustentável, abrangendo a sua rede de relacionamento.

\section{Disseminação do Conhecimento}

A organização do conhecimento técnico e científico da Empresa "X", para fins de disseminação, deve ser incentivada, sistematizada e avaliada preservando os interesses da Entidade.

A disseminação do conhecimento na Empresa " $X$ " deve ser planejada, sistematizada e avaliada, abrangendo a sua rede de relacionamento (a disseminação do conhecimento se desenvolve bidirecionalmente, ou seja, do ambiente externo para a organização e vice-versa).

Desenvolvimento de Competências

O processo de Gestão de Pessoas na Empresa "X" deve seguir as premissas do Modelo de Gestão por Competências.

O modelo de Educação Continuada da Empresa " $X$ " deve garantir a permanente criação, desenvolvimento e atualização das competências individuais necessárias.

Fonte: Gouvêa da Costa et al. (2005)

Figura 14 - Diretrizes estratégicas para implantação da Gestão do Conhecimento 


\section{Considerações finais}

As diretrizes estratégicas representam elementos diretivos e de controle estratégico para a implantação da Gestão do Conhecimento em uma empresa, na medida em que orientam a sua implantação e integram as diferentes políticas e programas da organização para a Gestão do Conhecimento.

O "processo" desenvolvido neste trabalho integra e relaciona os seguintes elementos: um modelo organizacional baseado no conhecimento; os desafios e aplicações da Gestão do Conhecimento nas empresas; os processos organizacionais e de gestão para o conhecimento organizacional; o desenvolvimento de uma visão estratégica para a Gestão do Conhecimento; a descrição de uma abordagem metodológica fundamentada em um processo participativo e sistêmico para a implantação da Gestão do Conhecimento; e um conjunto de premissas e de diretrizes estratégicas definidas na perspectiva de seu conteúdo, estrutura e dinâmica.

As diretrizes estratégicas têm um domínio que é estabelecido pelo processo empresarial ou corporativo para a Gestão do Conhecimento, através de suas funções e práticas. Têm a sua estrutura definida por um modelo de gestão que se baseia nos elementos básicos de uma "organização do conhecimento". As diretrizes também estabelecem relações de causa-efeito que representam a dinâmica de criação, retenção, difusão e desenvolvimento do conhecimento organizacional.

Este trabalho contribui para o desenvolvimento de uma estratégia empresarial fundamentada no conhecimento organizacional e estabelece os mecanismos para a gestão estratégica do conhecimento, desenvolvendo uma visão sistêmica e orientada a processos.

Finalmente, tem-se, com a definição das diretrizes estratégicas para a Gestão do Conhecimento para uma organização, o desenvolvimento de uma arquitetura estratégica para a implantação de um processo corporativo de Gestão do Conhecimento.

\section{Referências}

AMESSE, F.; COHENDET, P. Technology transfer revisited from the perspective of the knowledge-based economy. Research Policy, v. 30, n. 9, p. 1459-1478, 2001.

APRIL, K. A. Guidelines for developing a k-strategy. Journal of Knowledge Management, v. 6, n. 5, p. 445456, 2002.

ARGYRIS, C. Knowledge for action: a guide to overcoming barriers to organizational change. San Francisco: Jossey-Bass, 1993.
AUGIER, M.; KNUDSEN, T. The architecture and design of the knowledge organization. Journal of Knowledge Management, v. 8, n. 4, p. 6-20, 2004.

BECKMAN, T. The Current State of Knowledge Management. In: LIEBOWITZ, J. (Ed.) Knowledge Management Handbook. New York: CRC Press, 1999.

BROWN, J. S.; DUGUID, P. Knowledge and organization: a social-practice perspective. Organization Science, v. 12, n. 2, p. 198-213, 2001.

BUENO, E. El capital intangible como clave estratégica en la competencia actual. Boletín de Estudios Económicos, v. 53, n. 164, p. 207-209, 1998.

BUENO, E. Organización de empresas: estructura, procesos y modelos. Madrid: Pirámide, 1997.

CARAYANNIS, E. G. Knowledge transfer through technological hyperlearning in five industries. Technovation, v. 19, n. 3, 1999.

COHEN, W. M.; LEVINTHAL, D. A. Aborptive capacity: a new perspective on learning and innovation. Administrative Science Quaterly, v. 35, n. 1, p. 128-152, 1990.

COUGHLAN, P.; COGHLAN, D. Action research for operations management. International Journal of Operations \& Production Management. v. 22, n. 2, p. 220-240, 2002.

DAVENPORT, T. H.; PRUSAK, L. Conhecimento empresarial: como as organizações gerenciam o seu capital intelectual. Rio de Janeiro: Campus, 1998.

DE HOOG, R. CommonKADS: knowledge acquisition and design support methodology for structuring the KBS integration process. In: LIEBOWITZ, J.; WILCOX, L. C. (eds). Knowledge management and its integrative elements. Boca Raton: CRC Press, 1997, p. 129-141.

DEL REY CHAMORRO, F. M.; ROY, R.; VAN WEGEN, B.; STEELE, A. A framework to create key performance indicators for knowledge management solutions. Journal of Knowledge Management, v. 7, n. 2, p. 46-62, 2003.

FLEURY, A.; FLEURY M. T. L. Aprendizagem e inovação organizacional: as experiências de Japão, Coréia e Brasil. Atlas. 2. ed. São Paulo, 1997.

FROHLICH, M. T. Techniques for improving response rates in OM survey research. Journal of Operations Management, v. 20, n. 1, p. 53-62, 2002.

GARVIN, D. A. Building a learning organization. Harvard Business Review. v. 71, n. 4, p. 78-91, 1993. 
GOOIJER, F. Designing a knowledge management performance framework. Journal of Knowledge Management, v. 4, n. 4, p. 303-310, 2000.

GOUVEA DA COSTA, S.; JARA, J.; SORIA, M. A. Z.; GODOY TORALES, R. Alinhando a gestão do conhecimento com a estratégia da empresa: o caso Itaipu Binacional. In: VISEMINÁRIONACIONALDA GESTÃODA INFORMAÇÃOE DO CONHECIMENTO NO SETOR DE ENERGIA ELÉTRICA - SINCONEE, 6., Recife, 2005. Anais...Brasília: ELETROBRÁS, 2005, p. 1-9.

HARRINGTON, J. Aperfeiçoando Processos Empresariais. São Paulo: Makron Books, 1993.

HOLTSHOUSE, D. Knowledge research issues. California Management Review, v. 40, n. 3, p. 277-288, 1998.

HUNG, Y. C.; HUANG, S. M.; LIN, Q. P.; TSAI, M. L. Critical factors in adopting a knowledge management system for the pharmaceutical industry. Industrial Management and Data Systems, v. 105, n. 2, p. 164183, 2005.

KAKABADSE, N. K.; KAKABADSE, A.; KOUZMIN, A. Reviewing the knowledge management literature: towards a taxonomy. Journal of Knowledge Management, v. 7, n. 4, p. 75-91, 2003.

KIM, Y. G.; YU, S. H.; LEE, J. H. Knowledge strategy planning: methodology and case. Expert systems with applications, v.24, n.3, p. 295-307, 2003.

KING, W. R. The effective knowledge organization. Business Process Management, v.9, n.3, p. 259-260, 2003.

KING, W. R.; MARKS Jr., P. V.; MCCOY, S. The most important issue in knowledge management. Communications of the ACM, v. 45, n. 9, p. 93-97, 2002.

KLASSEN, R. D.; JACOBS, J. Experimental comparison of web, electronic and mail survey technologies in operations management. Journal of Operations Management, v. 19 , n. 6 , p. 713-728, 2001.

LEE, S. M.; HONG, S. An enterprise-wide knowledge management system infrastructure. Industrial Management and Data Systems, v. 102, n. 1, p. 17-25, 2002.

LIN, C.; TSENG, S. M. The implementation gaps for the knowledge management system. Industrial Management and Data Systems, v. 105, n. 2, p. 208-222, 2005.

MAIER, R.; REMUS, U. Implementing process-oriented knowledge management strategies. Journal of Knowledge Management, v. 7, n. 4, p. 62-74, 2003.
MALONE, J. D. Shooting the past: an instructional case for knowledge management. Journal of Information Systems, v. 17, n. 2, p. 41-49, 2003.

MILLS, J.; NEELY, A.; PLATTS, K.; GREGORY, M. Manufacturing strategy: a pictorial representation. International Journal of Operations \& Production Management. v. 18, n. 11, p. 1067-1085, 1998.

NADLER, D.; GERSTEIN, M. S.; SHAW, R. B. Arquitetura organizacional: a chave para a mudança empresarial. 2. ed. Rio de Janeiro: Campus, 1994.

NONAKA, I. e TAKEUCHI, H. Criação de conhecimento na empresa: como as empresas japonesas geram a dinâmica da inovação. Rio de Janeiro: Campus, 1997.

NONAKA, I.; KONNO, N. The concept of "ba": building foundation for knowledge creation. California Management Review, v. 40, n. 3, p. 40-54, 1998.

NONAKA, I; RYOKO, T. The knowledge-creating theory revisited: knowledge creation as a synthesizing process. Knowledge Management Research \& Practice, n. 1, p.2-10, 2003.

OKUMUS, F. A framework to implement strategies in organizations. Management decision, v. 41, n. 9, p. 871-882, 2003.

OLSON, E. M.; SLATER, S. F.; HULT, G. T. M. The importance of structure and process to strategy implementation. Business Horizons, v. 48, n. 1, p. 47-54, 2005.

PAI, D. C. Knowledge strategies in Taiwan's IC design firms. Journal of American Academy of Business, v. 7 , n.2, p. 73-77, 2005.

PINHEIRO DE LIMA, E. Uma modelagem organizacional baseada em elementos de natureza comportamental. Florianópolis, 2001. Tese (Doutorado). Programa de Pós-Graduação em Engenharia de Produção, Departamento de Engenharia de Produção e Sistemas, Universidade Federal de Santa Catarina - UFSC.

PINHEIRO DE LIMA, E.; LEZANA, A. G. R. Competence-based levels: an integrative review. In: INTERNATIONAL CONFERENCE ON THE MANAGEMENT OF TECHNOLOGY - IAMOT'99, 8., 1999, Cairo. Proceedings...Cairo: IAMOT, Egito. 1 CD ROM, 1999.

PLATTS, K. A process approach to researching manufacturing strategy. International Journal of Operations \& Production Management, v. 13, n. 8, p. 4-17, 1993.

PLATTS, K. Characteristics of methodologies for manufacturing strategy formulation. Computer Integrated Manufacturing Systems, v. 7, n. 2, p. 93-99, 1994. 
PLATTS, K.; MILLS, J.; BOURNE, M.; NEELY,A.; RICHARDS, H.; GREGORY, M. Testing manufacturing strategy formulation processes. International Journal of Production Economics, v. 56-57, p. 517-523, 1998.

\section{PLATTS, K.; MILLS, J.; NEELY, A.; GREGORY, M.;} RICHARDS, H. Evaluating manufacturing strategy formulation processes. International Journal of Production Economics, v. 46-47, p. 233-240, 1996.

RUGGLES, R. The state of the notion: knowledge management in practice. California Management Review, v.40, n.3, p. 80-89, 1998.

SANCHEZ, R.; HEENE, A. Competence-based strategic management: concepts and issues for theory, research, and practice. In: (eds.). Competence-based strategic management. Chichester: John Wiley and Sons, p. 3-42, 1997.

SANTOS, A. R.; PACHECO, F. F.; PEREIRA, H. J.; BASTOS Jr., P. A. Gestão do conhecimento como modelo empresarial. In: (org.) Gestão do conhecimento: uma experiência para o sucesso empresarial. Curitiba: Champagnat, 2001.

SENGE, P. M. A quinta disciplina. São Paulo: Best Seller,1990.

SMITH, A. D. Knowledge management strategies: a multicase study. Journal of Knowledge Management, v. 8, n. 3, p. 6-16, 2004.

SNYMAN, R.; KRUGER, C. J. The interdependency between strategic management and strategic knowledge management. Journal of Knowledge Management, v. 8, n. 1, p. 5-19, 2004.

SOR, R. Information technology and organizational structure: vindicating theories from the past. Management Decision, v. 42, n. 2, p. 316-329, 2004.

SVEIBY, K. E. The new organizational wealth: managing and measuring knowledge-based assets. San Francisco: Berret-Koehler, 1997.
TEECE, D. Research directions for knowledge management. California Management Review, v. 40, n. 3, p. 289-292, 1998.

TERRA, J. C. C. Gestão do Conhecimento: Aspectos Conceituais e Estudo Exploratório Sobre as Práticas de Empresas Brasileiras. Tese de Doutorado. Universidade de São Paulo, 1999.

TERRA, J. C. C. Gestão do conhecimento: o grande desafio empresarial. Negócio. São Paulo, 2000.

VERKASALO, M.; LAPPALAINEN, P. A method of measuring the efficiency of the knowledge utilization process. IEEE Transactions on Engineering Management, v. 45, n. 4, p. 414-423, 1998.

VOGELS, W. Technology challenges for the global realtime enterprise. Journal of Knowledge Management, $\mathrm{v}$. 8, n. 4, p. 100-104, 2004.

WENGER, E. Knowledge management as doughnut: shaping your knowledge strategy through communities of practice. Ivery Business Journal, jan./fev., p. 1-8, 2004.

WIIG, K. M. What future knowledge management users may expect. Journal of Knowledge Management, v. 3, n. 2, p. 155-165, 1999.

WONG, K. Y. Critical success factors for implementing knowledge management in small and medium enterprises. Industrial Management and Data Systems, v. 105, n. 3, p. 261-279, 2005.

ZACK, M. H. Developing a knowledge strategy: epilogue. Disponível em: <http://web.cba.neu.edu/ $\sim$ mzack/articles/kstrat2/kstrat2.htm> Acesso em: 01 ago. 2005.

ZACK, M. H. Rethinking the knowledge-based organization. Sloan Management Review, v. 44, n. 4, p. 6771, 2003. 
